\begin{tabular}{|c|l|}
\hline Title & A synchronous local dynamics contributes to stability of a seagrass bed in Tokyo Bay \\
\hline Author(s) & Yamakita, Takehisa; W atanabe, Kentaro; Nakaoka, Masahiro \\
\hline Citation & $\begin{array}{l}\text { Ecography, 34(3), 519-528 } \\
\text { https:/doi.org/10.1111/.1600-0587.2010.06490.x }\end{array}$ \\
\hline Issue Date & 2011-06 \\
\hline Doc URL & http://hdl.handle.net/2115/49338 \\
\hline Rights & The definitive version is available at www.blackwell-synergy.com \\
\hline Type & article (author version) \\
\hline File Information & Eco34_3_519-528.pdf \\
\hline
\end{tabular}

Instructions for use 


\title{
Asynchronous local dynamics contribute to the stability of a seagrass bed in Tokyo Bay
}

\author{
Takehisa Yamakita, Kentaro Watanabe, Masahiro Nakaoka \\ Correspondence to T.Yamakita (yamakita3@gmail.com), Department of Forest Entomology, Forestry and Forest Products Research Institute, Tsukuba, Ibaraki, \\ 305-8687, Japan \\ - K.Watanabe and M. Nakaoka, Akkeshi Marine Station, Field Science Center for Northern Biosphere, Hokkaido University, Akkeshi, Hokkaido 088-1113, Japan.
}

\begin{abstract}
:
It is known that asynchronous temporal variations in local populations can contribute to the stability of metapopulations. However, studies evaluating the hierarchical organization of multiple spatial scales are rare for continuous marine landscapes, especially for marine vegetation such as seagrass beds. In this study, long-term observation (26 years) of temporal changes and nested spatial analyses were combined for an extensive seagrass meadow in Tokyo Bay, Japan, using remote sensing and geographic information system technologies. We examined how the dynamics at the whole-bed scale $\left(\sim 1 \mathrm{~km}^{2}\right)$ are related to those at a local scale $\left(0.04 \mathrm{~km}^{2}\right)$, and investigated the relationship between the seagrass dynamics and long-term changes in environmental conditions using data on oceanography, water quality, and sediment dynamics. The seagrass bed size fluctuated between a maximum of $1.28 \mathrm{~km}^{2}$ (in 1987) and a minimum of $0.39 \mathrm{~km}^{2}$ (in 2001), with an average of $0.90 \mathrm{~km}^{2}$. The temporal variation in seagrass bed size at the whole-bed scale correlated with sand movement within the seagrass bed related to changes in the position of a sandbar. Seagrass bed size fluctuated asynchronously at a local scale. Multivariate analyses recognized clusters of local areas showing similar patterns of fluctuation. Temporal patterns in the various clusters responded differently to changes in environmental factors, e.g., the position of the sandbar was highly correlated with seagrass bed size in shallow habitats but not in deeper areas. The magnitudes of the temporal variations for the local clusters were greater than that of the entire bed, suggesting that asynchronous fluctuation in different areas of the bed plays an important role in the overall stability of the seagrass bed. The results of the present study also highlight the importance of physical processes in regulating the temporal dynamics of seagrass beds in shallow sedimentary landscapes.
\end{abstract}

Key words: remote sensing, eelgrass, spatial scale, time series, Zostera spp.

The importance of spatial scales in interpreting declines in seagrass beds have occurred worldwide due ecological phenomena has long been recognized (Levin to human-induced environmental deterioration (McRoy 1992, Schneider 2001) and studies incorporating hierarchical organization of spatial scales have contributed greatly to the understanding of the relationships between local processes and global patterns (O'Neil and King 1998, Guichard et al. 2000, Nakaoka and Noda 2004). In discrete metapopulation systems, for example, it is well known that asynchronous temporal fluctuations among local populations contribute to stability at a metapopulation level (Hanski1999, Ranius 2001). However, only a few studies have analyzed the long-term temporal dynamics of populations in continuous landscapes (seascapes) at differing spatial scales of observation (Turner 2002, Pech 2007). This is especially true for marine populations, for which studies incorporating spatially explicit approaches in landscapes are still at an early stage of development (Robbins and Bell 1994, Bell et al. 2006). 1996, Short and Wyllie-Echeverria 1996, Duarte 2002, Orth et al.2006, Waycott et al. 2009). Patterns of temporal change in seagrass beds differ both spatially and temporally depending on the scale and intensity of environmental impacts (Larkum and West 1990, Frederiksen et al. 2004a). Analyses incorporating information on the landscape properties of seagrass beds have great potential for understanding how seagrass dynamics are affected by multiple factors operating at various spatio-temporal scales (Bell et al. 1999, 2006, Robbins and Bell 2000, Kendrick et al. 2005, 2008). Recent developments in computer and image analysis techniques have enabled researchers to analyze changes in seagrass beds at a landscape level over broad spatial scales and long time scales (e.g. Kendrick et al.2002, 2005, Yamakita and Nakaoka 2009).

In Tokyo Bay, Japan, seagrasses were a primary component of the coastal landscape until the early 20th Seagrass beds form productive coastal habitats, century; most seagrass beds disappeared due to coastal harboring a wide array of associated faunal assemblages development and eutrophication during the second half (Hemminga and Duarte 2000). However, massive of the century (Aioi and Nakaoka 2003). However, there 
is the possibility that seagrass beds may recover due to maps, land management, and topographical surveys). improvements in water quality in Tokyo Bay during and The photographs were taken on sunny days between after the 1980s (Furukawa and Okada 2006). Currently, January and March (except for 1984 when the only three seagrass beds remain in inner Tokyo Bay, the photograph was taken in May) from a height of $2000 \mathrm{~m}$. largest of which is located on the Futtsu tidal flat in eastern Tokyo Bay. High-resolution aerial photographs of this area are available for each of the past 30 years (Yamakita et al. 2005), providing an opportunity to The photographs were black and white before 1988 and colored thereafter. The tidal height when the photographs were taken varied from a maximum of +0.39 m mean tide level in 2001 to a minimum of -0.99 analyze long-term changes in the seagrass bed at various $\mathrm{m}$ in 1984, with an average of $-0.02 \pm 0.31 \mathrm{~m}$ based on spatial scales using remote sensing and GIS techniques. the hourly sea level) data provided by Japan Ocean Data The goals of this study were to analyze the long-term and broad-scale spatial dynamics of the Futtsu seagrass bed in Tokyo Bay and to examine factors affecting its dynamics. In particular, we addressed how spatial asynchrony at a small scale is related to the Center (JODC; http://www.jodc.go.jp/) .

Digitized pictures were ortho rectified and resampled to $0.5 \mathrm{~m}$ resolution, which is greater than lowest resolution of the photographs. We chose $0.5 \mathrm{~m}$ resolution because it is consistent with the annual stability of the whole seagrass bed size (constancy of the horizontal growth rate of seagrasses $(\sim 0.6 \mathrm{~m}$ for $Z$. distribution and biomass; Grimm and Wissel 1997). To japonica and $0.3 \mathrm{~m}$ for Z. marina; Marbá and Duarte achieve this goal, we compared patterns of temporal fluctuation in seagrass vegetation among various parts of the bed by dividing it into $0.04 \mathrm{~km}^{2}$ grid areas. We also examined whether the temporal dynamics in 1999, Lee et al. 2005), and thus can be used for analysis of seagrass growth dynamics. To extract

seagrass-vegetated areas from the color photographs, we applied supervised classification with the maximum different areas were related to different environmental or likelihood method using ER-Mapper (Version 6.3 Earth biological factors using long-term data on oceanography, Resource Mapping; Jensen 1996). For monochrome meteorology, water quality, topography, and species distribution.

\section{Methods}

\section{Study site}

Tokyo Bay is $80 \mathrm{~km}$ long trending north to south (Fig. 1a). The bay is separated into inner and outer areas by a $7 \mathrm{~km}$-wide strait between Cape Futtsu and Cape Kannon. The inner bay has more limited water exchange than the outer bay, with an average water depth of $15 \mathrm{~m}$ (Furukawa and Okada 2006). Three seagrass species, Zostera caulescens Miki., Z. japonica Aschers. and Graebn., and Z. marina L. occur in the inner bay.

The seagrass bed on the Futtsu tidal flat is the largest in Tokyo Bay, and is situated along the northern shore of Cape Futtsu (Fig. 1a, b). The dominant species is eelgrass (Z. marina), which occurs mainly from the lower intertidal to shallow subtidal zone ( 1-2 m deep; Fig. 1d, e). Z. japonica inhabits the intertidal zone, and $Z$. caulescens is found in the deepest part of the bed $(\sim 2-4$ m; Fig. 1d, e). The eastern part of the seagrass bed was land-filled in 1971 and canal for that was filled in 1984. Some anthropogenic disturbance, such as raking for clams (Ruditapes philippinarum) by local fishermen, was constantly observed along the eastern near shore line (around of VI-12 in Fig. 1e).

\section{Measurement of the seagrass area}

We used high-resolution aerial photographs taken annually between 1980 and 2005 to estimate the seagrass area. Photographs were taken by Keiyou Sokuryo Co. Ltd. for the purposes of aerial photogrammetry for general use (e.g., city maps, road pictures, we binarized the images using a threshold that was visually selected after correction of lib darkening following the method of Frederiksen et al. (2004b). The visual threshold was defined by the structure (patch or gap) of the seagrasses in both the shallower and deeper areas that could be clearly seen without noise. We compared the two methods by using photographs from 1988 to 2005, and found no significant differences in the estimated seagrass bed size (pair-wise t-test: $\mathrm{T}=-0.79$, $\mathrm{p}=0.44, \mathrm{n}=17$ ). The extent of the study area was set to $2.67 \mathrm{~km}^{2}$, which covered $\sim 80 \%$ of the entire seagrass bed (Fig. 1c). The remaining 20\% corresponded to the periphery of the seagrass bed and was excluded from the analyses because the extracted images contained misclassifications caused by depth, reflectance of sunlight, and seaweed (Porphyra yezoensis) aquacultures. The accuracy of the classification within the study area was validated by comparison with a field survey conducted in May 2004. The seagrass coverage within a $5 \mathrm{~m}$ region of each of 54 points (marked with a portable GPS with an accuracy of 3-5 m) was recorded and compared to the classification resulting from the images taken in the previous year. The accuracy of seagrass discrimination based on the images was $65 \%$ ( 35 out of 54 were correctly identified). The errors occurred because vegetation with $<30 \%$ coverage could not be discerned in the photographs. Excluding points with vegetation $<30 \%$ resulted in a higher discrimination rate ( $81 \%$ of $Z$. marina was correctly discriminated). The three seagrass species could not be separated based on the photographs.

Using the images, we measured the size of the seagrass bed and the distance from the shoreline to the offshore border of the seagrass bed along three transects (Lines E, M, and W in Fig.1c). The seagrass bed size represented distribution and coverage of seagrass, and the lines represented distribution at the edge of the bed. 

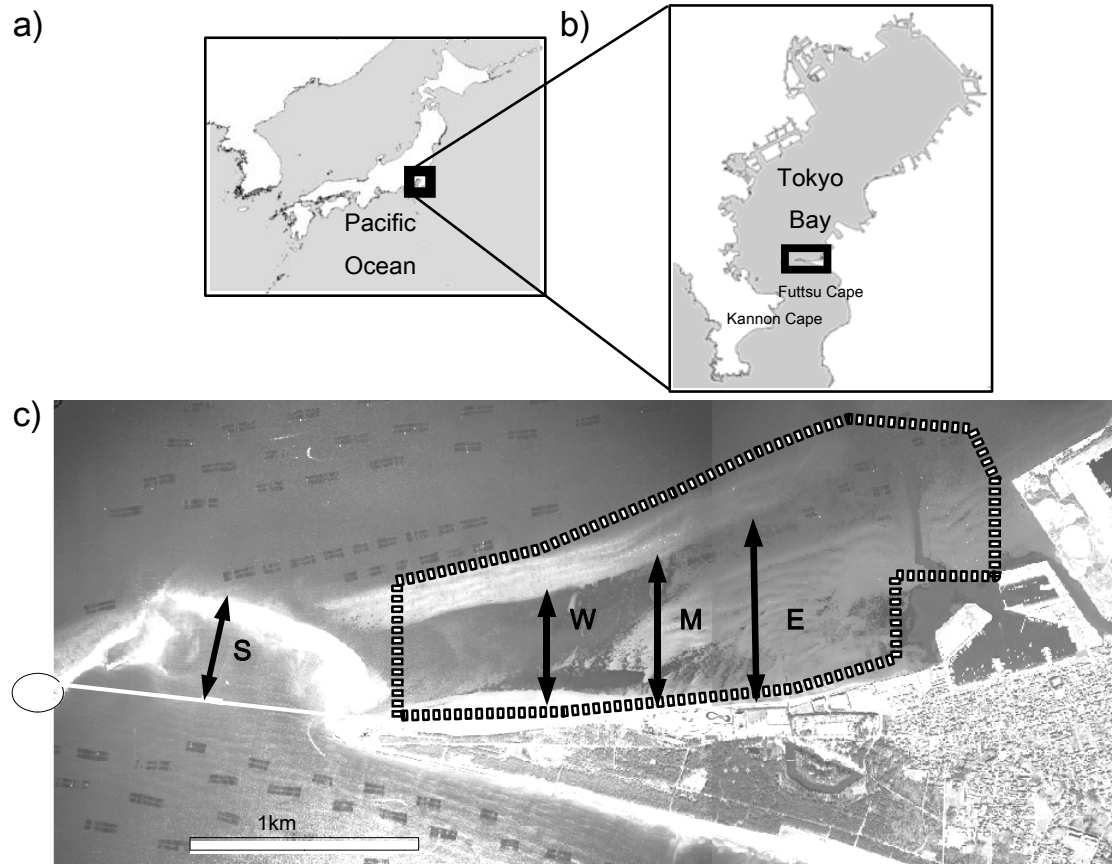

d)

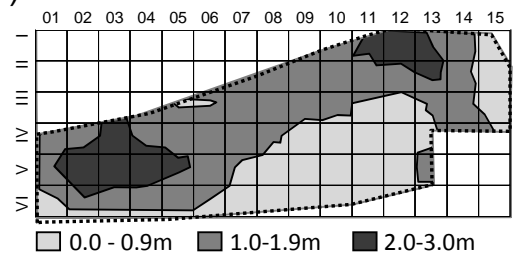

e)

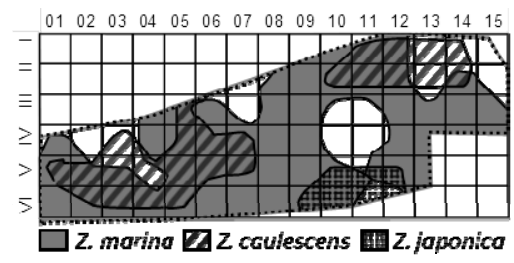

Figure 1 Maps (a,b,d,e) and an aerial photograph (c; taken in 2003) showing the feature of study site. Dotted line shows the study area for the analysis (a,b). The distance from the shoreline to the offshore border of the seagrass bed (linesW, M and E) and the sandbar (S) is indicated by arrows (c). Rectangular structures at the outer parts of the image were seaweed (Porphyra tener) aquaculture. Water depth (d) and species composition of seagrasses (e; based on the survey conducted by Marine Biological Research Institute of Japan Co. Ltd in 2003) at the study site were shown with the subdivided grids each $200 \times 200 \mathrm{~m}$.

For some years, the border of the seagrass bed could not sandbar and the extension of the shoreline, i.e., a line be defined due to low density or patchy spatial seagrass connecting the tip of the cape and the artificial island distribution (2004 in M and 1983, 1985 in W). These years were excluded from the analyses. The study area $\left(2.67 \mathrm{~km}^{2}\right)$ was divided into local areas using a $200 \times$ (Fig. 1b; Line S).

To represent the magnitude of the waves caused $200 \mathrm{~m}$ grid, which was consistent with the length of the effective fetch (WEF), which is the relative value of sand dune and gutter along the direction of the transects. wind speed accumulation $>5 \mathrm{~m}$ in each direction The grid areas were named from the northwest corner (I-01) to the southeast corner (VI-15) (Fig. 1d, e). weighted by the distance from land, and expressed as follows (Frederiksen et al. 2004b):

\section{Long-term changes in environmental variables}

The Futtsu tidal flat undergoes substantial topographical changes due to the physical effects of drifting sand, stray tidal currents, and the winter monsoon wind (Furukawa and Okada 2006). We used changes in the position of the sandbar as an indicator of topographic change due to drifting sands (Mills and Fonseca 2003, Bradley and Stolt 2006, Cabaço and Santos 2007), because they were clearly observable in successive aerial photographs (Fig. 2). Sand movement caused direct burial and indirect changes in the depth structure. From the photographs, we measured the distance between the inflection point of the arch-shaped

$$
W E F=\sum_{j} \sum_{i} D_{i} \frac{\cos i}{5} \omega_{i j} f_{i j}
$$

Where $D_{i}$ is the distance to the opposite shore in a given direction, $i$ is the angle of the compass direction, $\omega$ is the average maximum wind speed per month, and $f$ is the frequency of observations for a given wind direction. Hourly wind speed data for Cape Kannon $\left(35.255^{\circ} \mathrm{N}, 139.747^{\circ} \mathrm{E}\right)$ provided by JODC were used for WEF calculations.

Water quality is known to influence seagrass cover (Short and Wyllie-Echeverria 1996, Orth et al. 2006). As indicators of water quality, we used the concentration of ammonium nitrogen $\left(\mathrm{NH}_{4} \mathrm{~N}\right)$ and 
1989

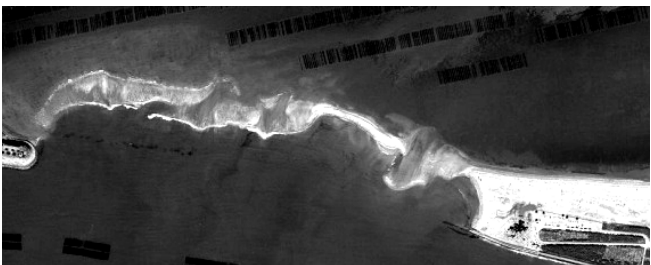

1995

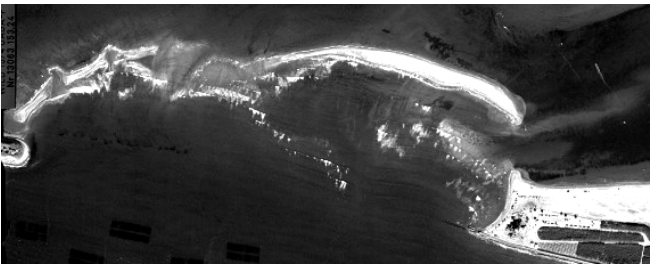

Figure 2 Changes in sandbar during the period of mass decline in seagrass bed (between 1989 and 1995).

transparency, which were measured at the center of inner Tokyo Bay by the Chiba Prefectural Fisheries Research Center (Ishii et al. 2008). Although there has been a water quality measurement station located $3 \mathrm{~km}$ offshore of our study site in recent years, we consider that the data for the central bay represent temporal variations in conditions near the seagrass bed, because the spatial variability of these parameters throughout inner Tokyo Bay was much smaller than their temporal variability. $\mathrm{NH}_{4} \mathrm{~N}$ was measured monthly at $1 \mathrm{~m}$ depth using the indophenol method until 1994 and using an auto-analyzer (TRAACS-800) thereafter. Transparency was simultaneously measured using a Secchi disk. Annual mean values were used for the statistical analyses; their temporal trends did not differ from those averaged only over the summer periods when the seasonal water quality was worst in Tokyo Bay. Summer water temperatures (mean, June-August) from the same dataset were also used, because high temperatures $>25$ ${ }^{\circ} \mathrm{C}$ negatively affect eelgrass (Marsh et al. 1986). Water temperature was measured using a cylindrical mercurial thermometer until 2000 and a salinity, temperature, and depth recorder (model AST1000) thereafter. The annual average sealevel of the bay was also obtained from the JODC sealevel dataset of Shibaura station $\left(35.637^{\circ} \mathrm{N}\right.$, $\left.139.754^{\circ} \mathrm{E}\right)$. This parameter represents changes in the immersion time in the shallow area where Z. japonica is dominant.

\section{Analyses}

Stability of seagrass vegetation, defined here as constancy in seagrass bed size, was represented by the coefficient of variation (CV), which measured magnitude of temporal fluctuation in seagrass meadow area. The seagrass bed (or a section of the bed) was regarded as more stable with smaller value of $\mathrm{CV}$. The seagrass bed size and the distance to the shoreline from the offshore seagrass bed borders were related to environmental factors by multiple regression analysis. Selection of environmental parameters was conducted using the AIC (Akaike information criterion; Akaike 1974), which consists of the maximum log likelihood weighted by the number of parameters. The lowest-AIC model was selected after calculating regressions using all combinations of the parameters.

Similarities in the temporal patterns of fluctuation for the local seagrass areas were examined using the modified GOWER similarity index, which can directly compare different magnitudes of time series patterns (Anderson et al. 2006). We conducted cluster analysis of the similarity data using the group average method. To show asynchrony in the annual changes, we also obtained the $\mathrm{CV}$ for each cluster of local areas. The Mantel test was conducted to test relationships between the similarity matrix and the geographic distance matrix (Dale 2002). Spatial autocorrelation structures in temporal variations in the seagrass bed size were also examined using a spatial correlogram of Moran's I statistics (Legendre and Legendre 1998).

\section{Results}

\section{Long-term changes in the entire seagrass bed}

The size of the seagrass bed fluctuated greatly from year to year, with a maximum of $1.28 \mathrm{~km}^{2}$ (1987) and a minimum of $0.39 \mathrm{~km}^{2}$ (2001) (Fig. 3a). The average size of the seagrass bed during the study period was $0.90 \pm 0.24 \mathrm{~km}^{2}(\mathrm{CV}=0.26)$. The seagrass bed size fluctuated widely between 1980 and 1987, with rapid expansions in 1980-81 and 1984-86, and declines in 1982-83. Between 1987 and 1991, the size was stable at $\sim 1.2 \mathrm{~km}^{2}$. A substantial decline in area occurred between 1992 and 1993, after which the seagrass bed size was relatively stable at $\sim 0.8 \mathrm{~km}^{2}$. In the $2000 \mathrm{~s}$, the size declined again during 2000-01 and then increased from 2001 to 2003. Distance from the shoreline to the offshore border steadily decreased with time for all three transects (Fig. 3b).

a)
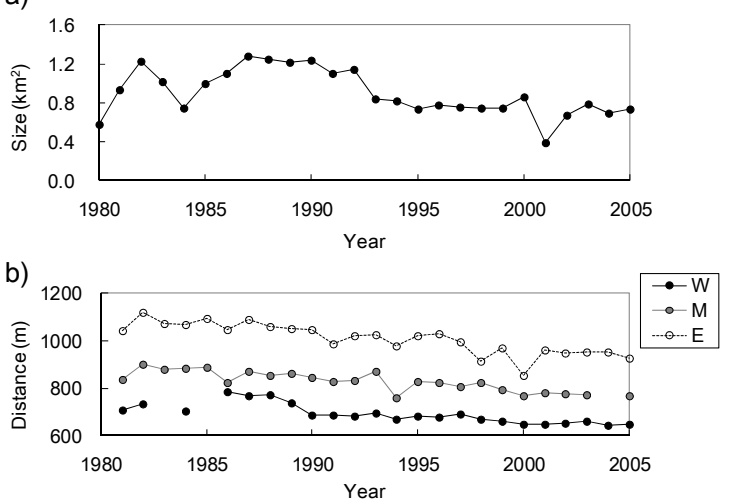

Figure 3 Temporal changes in total seagrass bed size from 1980 to 2005 (a), and in the distance from the shoreline to the offshore borders of the seagrass bed (b). W, M and E indicate different measurement line (see Fig. 1). 

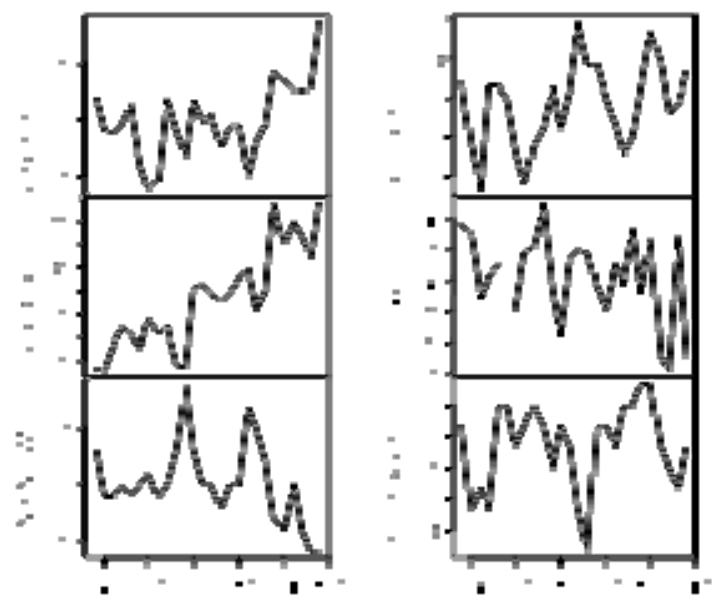

Figure 4 Temporal changes in environmental variables around Futtsu tidal flat and in Tokyo Bay. Sealevel of the bay, distance to the sandbar from the extent of coastline, ammonium nitrogen $\left(\mathrm{NH}_{4} \mathrm{~N}\right)$, transparency and WEF (weighted effective fetch). See text for the sources and methods of calculation for these variables.

\section{Relationships with environmental factors}

Patterns of temporal change varied greatly among the environmental variables. Water quality $\left(\mathrm{NH}_{4} \mathrm{~N}\right.$ and transparency) fluctuated widely, with an overall decreasing trend for $\mathrm{NH}_{4} \mathrm{~N}$ and an increasing trend for transparency. The distance from the shoreline to the sandbar generally increased with time. Sealevel fluctuated greatly, with an overall increasing trend since 1999 (Fig. 4). The WEF showed a decreasing trend with large annual fluctuations.

The results of model selection indicated that temporal fluctuations in the total seagrass bed size were negatively correlated with sandbar position, transparency, and WEF (Table 1). Temporal variations in offshore borders were primarily explained by sandbar position, which was negatively correlated with the distance to the borders (Table 1). Along transect W, the selected model also showed that the distance to the offshore border was negatively correlated with sealevel, $\mathrm{NH}_{4} \mathrm{~N}$, and positively with temperature.

\section{Temporal variations in seagrass bed size in different areas of the bed}

Patterns of temporal changes in seagrass bed size within each $200 \times 200 \mathrm{~m}$ area varied greatly from site to site. A cluster dendrogram comparing the similarity of temporal patterns indicated high similarity (height $=0.8$ ) for most pairs of areas (Fig. 5). At the 0.65 similarity level, three clusters (A to C) were distinguished, with three exceptional outliers $(\mathrm{O})$ at the edge of the study area.

Cluster $\mathrm{C}$ was further divided stepwise into six subgroups (C1-1 to $\mathrm{C} 3$ ). The contribution of seagrass abundance to overall seagrass coverage was highest for clusters C1-3 and C1-4, which each covered approximately $25 \%$ of the seagrass bed, and was lowest for cluster A (Table 2). The mean CV was the lowest for C1-3 $(\mathrm{CV}=0.33)$; however, all of the groups exceeded the $\mathrm{CV}$ for the total seagrass bed $(\mathrm{CV}=0.26$; Table 2$)$.

Groups of areas classified according to the cluster analysis were located in different parts of the seagrass bed (Fig. 6). Most areas belonging to B and C3 were located in the shallow part of the east side of the bed, and C1-1 along the western shallow coastline.

These three groups were separated by topography (deeper in C1-1) and vegetation type (sparser in B; Fig. 1 $\mathrm{d}$ and $\mathrm{c}) . \mathrm{C} 1-2, \mathrm{C} 1-3$ and $\mathrm{C} 1-4$ occupied the deeper part

\section{Table 1}

Result of model selection by multiple regression analysis between seagrass cover and environmental variables, i.e., annual average of sealevel (Sealevel), distance from shore to sandbar (Sandbar), tranceparency (Trance.), ammonium nitrogen $\left(\mathrm{NH}_{4} \mathrm{~N}\right)$, weighted effective fetch as representative of wind wave (WEF), and water tempereture (Temp.).

\begin{tabular}{|c|c|c|c|c|c|c|c|c|c|}
\hline & R-sq & $\begin{array}{c}\text { Adj } \\
\text { R-sq }\end{array}$ & $\mathrm{F}$ & $\mathrm{p}$ & $\overline{\mathrm{AIC}}$ & & Beta & $\mathrm{t}$ & $P$ \\
\hline \multirow[t]{4}{*}{ Bed size } & 0.49 & 0.42 & 6.8 & $<0.01$ & -10.11 & & & & \\
\hline & & & & & & Sandbar & -0.42 & 4.88 & 0.06 \\
\hline & & & & & & Trance. & -0.47 & -2.00 & 0.01 \\
\hline & & & & & & WEF & -0.24 & -2.69 & 0.22 \\
\hline \multirow[t]{6}{*}{ W } & 0.67 & 0.57 & 6.8 & $<0.01$ & 224.72 & & & & \\
\hline & & & & & & Sealevel & -0.54 & 2.02 & 0.02 \\
\hline & & & & & & Sandbar & -0.78 & -2.49 & $<0.01$ \\
\hline & & & & & & $\mathrm{NH}_{4} \mathrm{~N}$ & -0.47 & -3.62 & 0.03 \\
\hline & & & & & & WEF & -0.25 & -2.34 & 0.15 \\
\hline & & & & & & Temp. & 0.33 & -1.51 & 0.05 \\
\hline \multirow[t]{2}{*}{ M } & 0.61 & 0.59 & 34.4 & $<0.01$ & 230.62 & & & & \\
\hline & & & & & & Sandbar & -0.78 & 44.54 & $<0.01$ \\
\hline \multirow[t]{4}{*}{ E } & 0.68 & 0.64 & 14.4 & $<0.01$ & 248.06 & & & & \\
\hline & & & & & & Sandbar & -1.01 & 10.12 & $<0.01$ \\
\hline & & & & & & $\mathrm{NH}_{4} \mathrm{~N}$ & -0.24 & -5.93 & 0.12 \\
\hline & & & & & & WEF & -0.19 & -1.60 & 0.21 \\
\hline
\end{tabular}




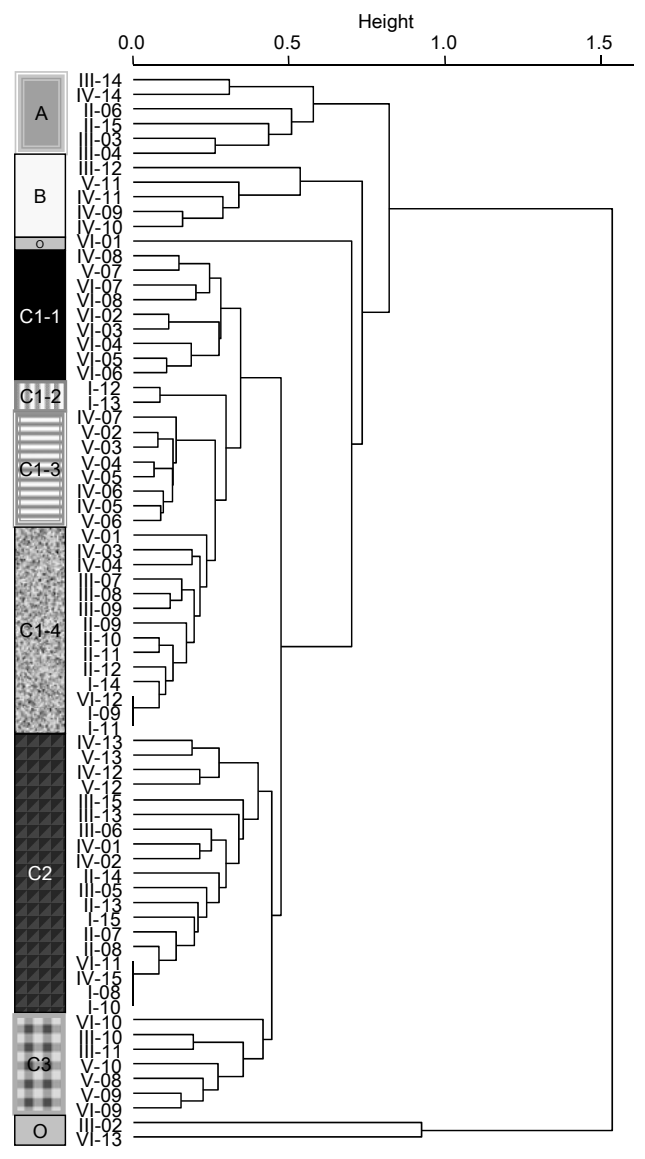

Figure 5 Cluster dendrogram showing modified GOWER similarity of temporal pattern in seagrass cover between pairs of grids. Groups were firstly devided into A to $\mathrm{C}$ (with three outliers) at the 0.65 height. Cluster $\mathrm{C}$ was then stepwisely divided into six subclusters (C1-1 to $\mathrm{C} 3$ ).

of the bed. C1-2 and C1-4 located in offshore of the eastern to middle positions of the bed and the former included a 2-3m-deep gutter behind the offshore bank where Z. caulacence mixed with Z. marina. C1-3

located the deeper western portion (a maximum of $3 \mathrm{~m}$ ) and was most stable. $\mathrm{C} 2, \mathrm{~A}$, and $\mathrm{O}$ were found at the northwestern and eastern edges of the seagrass bed.

Seagrass cover in clusters C1-3 and C1-4 sharply increased in the early 1980 s and tended to decrease after the early 1990s (Fig. 7). Clusters B, C1-1, and C3 exhibited a decreasing trend for seagrass cover, which in the latter two clusters has nearly disappeared since the mid-1990s. In contrast, seagrass cover in C1-2 rapidly

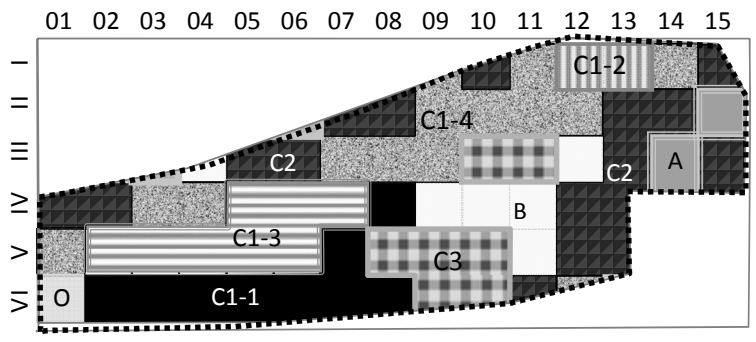

Figure 6 Geographical position of different groups of grids classified by the cluster analysis.

increased in the late 1980s. Temporal trends were not obvious for clusters A and $\mathrm{C} 2$.

Seagrass bed size was negatively correlated with sandbar position for the nearshore groups (B, C1-1, and C3; Table 3). WEF was negatively correlated with seagrass cover on the west side of the bed (C1-1 and $\mathrm{C} 1-3$ ). Water temperature was selected as a negative factor only on the deep west side where $Z$. calescence was present (C1-3). Sealevel was positively correlated with seagrass cover on the western nearshore side (C1-1, C3), while it was negatively correlated offshore except on the northeast side (C1-3, C2). Transparency was negatively correlated with seagrass cover for $\mathrm{B}, \mathrm{C} 1-4$, and $\mathrm{C} 2$, and $\mathrm{NH}_{4} \mathrm{~N}$ was positively correlated with seagrass cover at $\mathrm{C} 1-5$.

A significant negative correlation was found between the geographic distance matrix and the similarity matrix of the temporal patterns of seagrass cover for all pairs of areas (Mantel test, $\mathrm{r}=-0.16$, $\mathrm{p}<0.01)$. The distance dependency of Moran's I correlogram for all of the local areas identified positive spatial autocorrelation up to a distance of $\sim 0.5 \mathrm{~km}$ for most years (Fig. 8). Moran's I remained positive for longer distances in the early 1980 s than in later periods.

\section{Discussion}

The importance of local asynchrony on overall stability in population and community dynamics has been well addressed in discrete systems such as metapopulations and metacommunities (Hansky 1994, Dey and Joshi 2006). The present study provides a novel case demonstrating the importance of local asynchrony in determining large-scale dynamics in a continuous system. The quantitative data for long-term (25 years) inter-annual fluctuations in a seagrass bed consisting of

\section{Table 2}

Basic properties of the groups of grids showing similar temporal patterns of seagrass vegetation size change.

\begin{tabular}{ccccccccc}
\hline & A & B & C1-1 & C1-2 & C1-3 & C1-4 & C2 & C3 \\
\hline The number of grids & 5 & 6 & 9 & 2 & 8 & 14 & 19 & 7 \\
$\begin{array}{c}\text { Relative proportion of vegetation in total } \\
\text { seagrass size (\%) }\end{array}$ & 1.48 & 4.08 & 15.01 & 5.72 & 24.47 & 24.62 & 16.16 & 7.11 \\
$\begin{array}{c}\text { mean CV of each grid } \\
\text { (n) }\end{array}$ & 0.80 & 1.14 & 0.53 & 0.44 & 0.33 & 0.56 & 0.80 & 0.91 \\
\hline
\end{tabular}




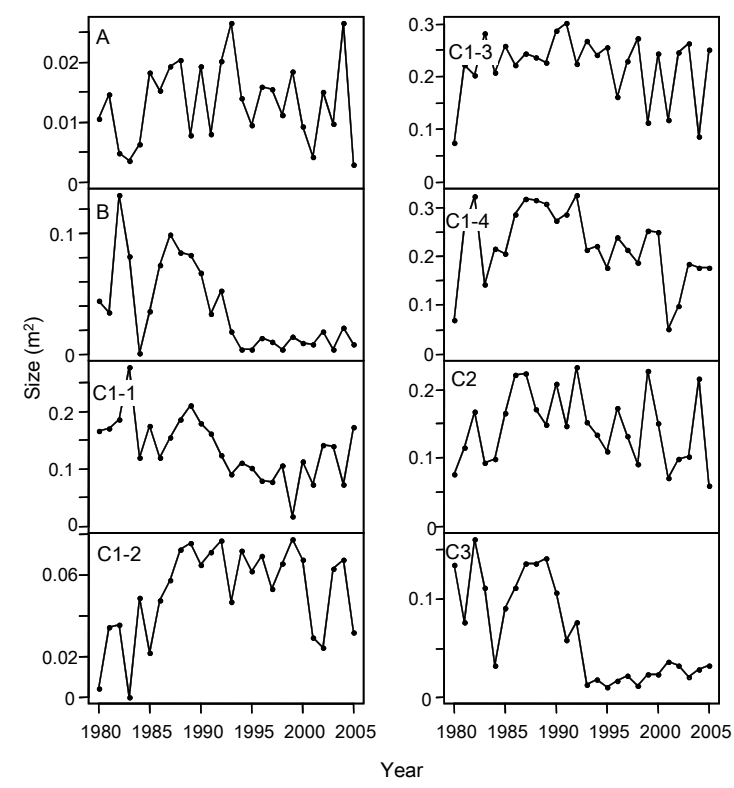

Figure 7 Temporal variation in seagrass bed sizes in each group of grids classified by the cluster analysis.

three Zostera species identified different patterns of temporal dynamics depending on location in the bed under differing environmental conditions.

The magnitudes of the temporal variations in the subdivided areas of the bed were greater than that of the entire bed. This suggests that spatial asynchrony in different areas of the bed plays an important role in temporal stability at a whole-bed spatial scale. Such scale-dependent processes in temporal dynamics have been demonstrated in studies of metapopulation ecology, in which the magnitude of temporal variability was shown to be greater for local populations than for the metapopulation (den Boer 1981, Hanski 1994, 1999). In the present study, for example, a decrease in the seagrass cover was observed in the early 1990s in clusters B, C1-1, and C3, whereas seagrass cover was stable in other areas (Fig. 7). Between 1990 and 2000, a rapid decline in the seagrass cover at $\mathrm{C} 1-3\left(0.2 \mathrm{~km}^{2}\right.$ decrease) was offset by an increase at $\mathrm{C} 2$ (by $0.14 \mathrm{~km}^{2}$ ) and in other areas, resulting in smaller overall changes in seagrass cover at the scale of the entire bed.

In contrast, spatial dependency was also observed at a local scale. As expected, patterns of temporal changes in seagrass cover were more similar between adjacent areas than for areas located farther apart. The observed similarity-distance relationships were consistent with the results of spatial autocorrelation, which was detected only within a distance of $0.5 \mathrm{~km}$, corresponding to $\sim 1-3$ grid cells (Fig. 8). A similar threshold distance for spatial correlation was found for seagrass beds in Western Australia (Kendrick et al. 2008).

The occurrence of asynchronous dynamics in different areas of the bed can be explained mostly by differing environmental conditions with topography (depth) and position (west or east) of the bed. For example, seagrasses in shallower areas may be more sensitive to changes in physical factors such as sand movement and physical disturbance (Duarte 2006, Cabaço and Santos 2008). In the present study, seagrass cover in shallow areas (clusters B, C1-1, and C3) was negatively affected by changes in the position of the sandbar (an indicator of sand drift). The western part of

Table 3

Result of stepwise multiple regression analysis relating temporal variation in environmental variables with that in seagrass cover at each group of grids. See Table 1 for the abbreviation of the predictor variables.

\begin{tabular}{|c|c|c|c|c|c|c|c|c|c|}
\hline Group & $R-s q$ & Adj R-sq & $\mathrm{F}$ & $\mathrm{P}$ & AIC & Predictor & Beta & $\mathrm{t}$ & $\mathrm{P}$ \\
\hline \multirow[t]{4}{*}{$\bar{A}$} & 0.23 & 0.12 & 2.07 & 0.14 & -176.69 & & & & \\
\hline & & & & & & Sealevel & -0.43 & -1.85 & 0.08 \\
\hline & & & & & & Sandbar & 0.38 & 1.43 & 0.17 \\
\hline & & & & & & WEF & 0.40 & 1.74 & 0.10 \\
\hline \multirow[t]{3}{*}{ B } & 0.48 & 0.43 & 10.20 & $<0.01$ & -103.65 & & & & \\
\hline & & & & & & Sandbar & -0.43 & -2.55 & 0.02 \\
\hline & & & & & & Trance. & -0.40 & -2.37 & 0.03 \\
\hline \multirow[t]{4}{*}{$\mathrm{C} 1-1$} & 0.48 & 0.40 & 6.43 & $<0.01$ & -81.75 & & & & \\
\hline & & & & & & Sealevel & 0.44 & 2.30 & 0.03 \\
\hline & & & & & & Sandbar & -0.96 & -4.34 & $<0.01$ \\
\hline & & & & & & WEF & -0.51 & -2.72 & 0.01 \\
\hline $\mathrm{C} 1-2$ & & No pr & & & & & & & \\
\hline \multirow[t]{4}{*}{$\mathrm{C} 1-3$} & 0.40 & 0.32 & 4.76 & 0.01 & -72.13 & & & & \\
\hline & & & & & & $\mathrm{NH}_{4} \mathrm{~N}$ & 0.36 & 2.10 & 0.05 \\
\hline & & & & & & WEF & -0.54 & -3.17 & $<0.01$ \\
\hline & & & & & & Temp. & -0.25 & -1.47 & 0.16 \\
\hline \multirow[t]{2}{*}{$\mathrm{C} 1-4$} & 0.41 & 0.38 & 15.95 & $<0.01$ & -65.28 & & & & \\
\hline & & & & & & Trance. & -0.64 & -3.99 & $<0.01$ \\
\hline \multirow[t]{4}{*}{$\mathrm{C} 2$} & 0.37 & 0.24 & 2.93 & 0.05 & -75.52 & & & & \\
\hline & & & & & & Sealevel & -0.47 & -2.07 & 0.05 \\
\hline & & & & & & Sandbar & 0.36 & 1.39 & 0.18 \\
\hline & & & & & & Trance. & -0.34 & -1.60 & 0.13 \\
\hline \multirow[t]{4}{*}{ C3 } & 0.56 & 0.50 & 8.99 & $<0.01$ & -90.05 & & & & \\
\hline & & & & & & Sealevel & 0.25 & 1.35 & 0.19 \\
\hline & & & & & & Sandbar & -0.68 & -3.77 & $<0.01$ \\
\hline & & & & & & Trance. & -0.35 & -2.12 & 0.05 \\
\hline
\end{tabular}




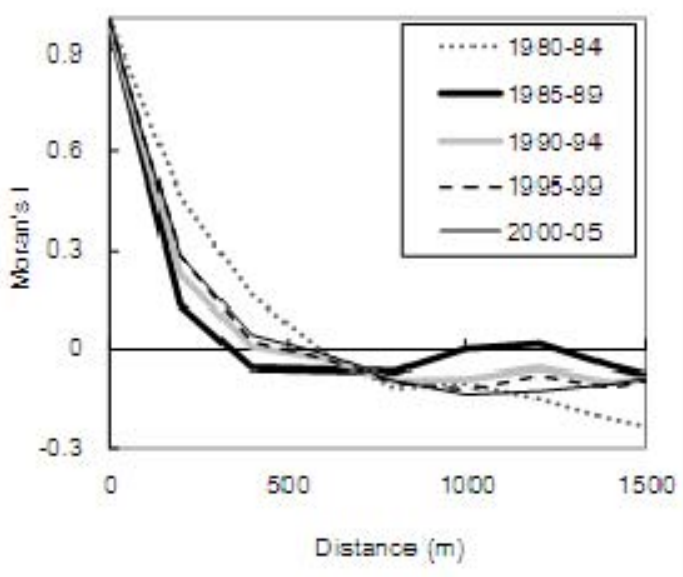

Figure 8 Morans' I correlogram for all $200 \times 200 \mathrm{~m}$ grids. Each line represent five (or four) year average between 1980 to 2005 .

the bed (C1-1 and C1-3) is more exposed to wave disturbance caused by the northwestern monsoon wind in winter, which may explain why WEF was negatively correlated with temporal changes in seagrass cover in these areas. In deeper areas (such as C1-2 and C1-3), however, seagrass cover was not correlated with the sandbar position, suggesting that sand movement was not an important factor driving temporal change for seagrasses in deeper areas. Although the reasons for the positive correlation for sandbar change at $\mathrm{C} 2$ remain unclear, these results suggest that the factors responsible for seagrass dynamics operated differently in different areas of the bed, which led to asynchronous seagrass dynamics within the overall bed.

Other factors causing the asynchronous dynamics include variation in species composition among different areas of the bed, as well as that in abundance (density and coverage) of each vegetation.

The dominant seagrass species in the shallow areas is the smaller species $Z$. japonica, which is more vulnerable to changes in physical stresses than Z. marina (Nakaoka and Aioi 2001, Mills and Fonseca 2003, Cabaço and Santos 2008). In contrast, Z.caulescens co-occurs with Z.marina at deeper areas. Z. caulescens exhibited different temporal dynamics compared to Z . marina with the former investing more resources to vertical growth of flowering shoots than horizontal growth by rhizome elongation (Nakaoka et al. 2003). It is likely that different species respond differently to environmental variables, contributing to different patterns of temporal fluctuations among positions. Finally, seagrass vegetation discerned by our methods is restricted to sites with $>30 \%$ coverage. The patchy and less dense vegetation, observed mostly at the peripheries of seagrass beds (e.g., C1-4 and C2), may exhibit greater fluctuations as they may have been classified as non-vegetated areas in years with low densities.

Due to the local asynchronicity in temporal fluctuations discussed above, seagrass cover changes over the entire seagrass bed were less variable than for each local area. The temporal fluctuation in the entire seagrass bed size was less than 4-fold, with a lower CV than reported in other studies (Table 4). A similarly low level of temporal fluctuation for a $\sim 1 \mathrm{~km}^{2}$-sized bed was also observed for the Amager and Samsø eelgrass beds in the Baltic Sea (Frederiksen et al. 2004b). Both of study sites are strongly affected by wind disturbance and possess surrounding sand dune structure. The effects of physical disturbance may vary in these sites depending on geography as in case of Futtsu seagrass bed. The results of the multiple regression analysis indicated that temporal changes in both the entire seagrass bed size and the distribution of the seagrass bed (offshore border) were related to the position of a sandbar, which we used as an indicator of physical disturbance due to drifting sand. From the 1970s to the 1980s, many land reclamation projects were undertaken in Tokyo Bay,

Table 4

Comparison of studies examining long-term fluctuation in Zostera seagrass beds.

\begin{tabular}{|c|c|c|c|c|c|c|c|c|}
\hline Ocean (Country) & Site name & Start & End & $\begin{array}{c}\text { The } \\
\text { num- } \\
\text { ber of } \\
\text { data }\end{array}$ & $\begin{array}{c}\text { Mean } \\
\text { Size } \\
\left(\mathrm{km}^{2}\right)\end{array}$ & SD & $\mathrm{CV}$ & Source \\
\hline \multirow[t]{2}{*}{ North Sea } & Holmstange & 1945 & 1995 & 8 & 0.08 & 0.06 & 0.74 & Frederiksen et al. (2004b) \\
\hline & Boddum & 1954 & 1998 & 8 & 0.12 & 0.09 & 0.72 & \\
\hline \multirow{3}{*}{$\begin{array}{l}\text { Baltic Sea } \\
\text { (Denmark) }\end{array}$} & Vejle & 1954 & 1999 & 7 & 0.04 & 0.02 & 0.45 & \\
\hline & Amager & 1954 & 1995 & 7 & 1.18 & 0.30 & 0.25 & \\
\hline & Samsø & 1954 & 1999 & 10 & 1.07 & 0.31 & 0.29 & \\
\hline North Atlantic & Glenan Archipelago & 1932 & 1990 & 9 & 7.45 & 1.31 & 0.18 & Glemarec et al. (1997) \\
\hline \multirow{4}{*}{$\begin{array}{l}\text { Bree lagoon } \\
\text { (French) }\end{array}$} & Pointe de I'Arc & 1944 & 2004 & 4 & 0.02 & 0.04 & 1.61 & \multirow[t]{4}{*}{ Bernard et al. (2007) } \\
\hline & Pointe de Berre & 1944 & 2004 & 4 & 0.22 & 0.41 & 1.86 & \\
\hline & Martigues & 1944 & 2004 & 4 & 0.05 & 0.08 & 1.68 & \\
\hline & Figuerolles & 1944 & 2004 & 4 & 0.07 & 0.13 & 1.73 & \\
\hline TokyoBay & Futtsu & 1980 & 2005 & 26 & 0.95 & 0.30 & 0.27 & This Study \\
\hline \multirow{6}{*}{$\begin{array}{l}\text { Seto Inland Sea } \\
\text { (Japan) }\end{array}$} & Iyo-nada & 1960 & 1989 & 5 & 8.62 & 4.04 & 0.47 & \multirow[t]{6}{*}{ Komatsu (1996) } \\
\hline & Suo-nada & 1960 & 1989 & 5 & 12.16 & 13.29 & 1.09 & \\
\hline & Aki-nada & 1960 & 1989 & 5 & 18.71 & 8.52 & 0.46 & \\
\hline & Bingo-Hiuchi-nada & 1960 & 1989 & 5 & 14.35 & 6.25 & 0.44 & \\
\hline & Bisan-seto & 1960 & 1989 & 5 & 39.33 & 40.47 & 1.03 & \\
\hline & Harima-nada & 1960 & 1989 & 5 & 7.75 & 7.69 & 0.99 & \\
\hline
\end{tabular}


including one at the eastern side of the Futtsu tidal flat. It has been argued that the land reclamation project changed the pattern of current flow along the coastal area of inner Tokyo Bay (Furukawa and Okada 2006, Nakayama 2006). We suggest that changes in the current flow and sand transportation caused by land reclamation likely affected the microgeography and topography of the area, as represented by the large change in the position of the sand bar (Fig. 2). Changes in the dynamics of seagrass vegetation in relation to those in microgeography and topography have been previously reported elsewhere (Marbá and Duarte 1995,Bradley and Stolt 2006, de Boer 2007).

The substantial decline in seagrass beds in other areas has mainly been attributed to changes in water quality (Shortand Wyllie-Echeverria 1996, Orth et al. 2006, Waycott et al. 2009). In our study, however, the temporal change in the size of the seagrass bed after the 1980s was negatively correlated with transparency. This pattern would be considered as artifact due to following reason. In Tokyo Bay, water quality was worst during the $1960 \mathrm{~s}$ to $1970 \mathrm{~s}$ (average transparency was $2.3 \mathrm{~m}$ in the 1960s and $2.7 \mathrm{~m}$ in the 1970s; Ishii et al. 2008), and has improved since the 1980s (Fig. 3; Furukawa and Okada 2006). Opposite to this improving trend in surface water quality, the seagrass bed size has been declining from a maximum of $1.24 \mathrm{~km}^{2}$ in $1970 \mathrm{~s}$ (Yamakita et al. 2005) to $0.69 \mathrm{~km}^{2}$ in the 2000s (average, 2000-2005). The trend in size during this study period does not seem to be related to water quality. Because much of the seagrass vegetation in this study area occurs in shallow $(>3 \mathrm{~m})$ areas, light was unlikely a major limiting factor. Alternatively, the decline in seagrass bed size is more likely related to physical processes such as sand drift which had been especially high after the landfill of coastal area during 1970's. As discussed above, those factors had caused pseudo correlation with water transparency. This importance of the physical effects of disturbance over light limitation has been experimentally demonstrated for other seagrass beds in shallow coastal regions (Duarte 2006, Cabaço and Santos 2008).

\section{Conclusions}

We examined the relationship between local seagrass dynamics and long-term temporal patterns in the overall seagrass landscape, and found that asynchronous spatial dynamics in different areas of the bed play an important role in maintaining the stability of the entire seagrass bed. Local differences were related to differing environmental conditions and geographic structures which also restrict species distribution. Our study also demonstrated that physical processes operating at large spatial scale, such as wave disturbance and sand movement, were responsible for long-term temporal changes in the shallow-water areas of the seagrass bed even under stability due to local asynchrony. Understanding such spatial asynchrony at a small spatial scale and its contribution to broad-scale seagrass dynamics is important to know the spatial scale of dynamics and causes. For the conservation of seagrass beds, these spatial orderings can help inform relevant management strategies, including the design of effective multi-scale seagrass monitoring methods and identification of important conservation units.

\section{Acknowledgement}

We are grateful to Center for Environmental Remote Sensing (CEReS), Chiba University for the facility of remote sensing and GIS analysis, and to Akihiko Kondoh for instructions of the analyses. We would like to thank Mitsuhiro Ishii and Futtsu Fisherman Union for cooperation in the fieldwork. Gary A. Kendrick and two anonymous reviewers kindly gave us valuable comments on the manuscript. This research was partly supported by the grants-in-aids from Nissei Foundation, Chiba Prefecture, the Ministry of Education, Science, Culture and Sports, Japan (No. 18201043, 14340242 and 21241055), Environment Research and Technology Development Fund, Ministry of the Environment Government of Japan (B-0910), and JSPS Research Fellowship (No.192341).

\section{Reference}

Aioi, K. and Nakaoka, M. 2003. The seagrasses of Japan. - In: Green E. P. and Short F. T. (eds) World atlas of seagrasses. University of California Press, Berkeley, USA. pp. 185-192.

Akaike, H. 1974. A new look at the statistical model identification.- IEEE transactions on automatic control 19: 716-723.

Anderson, M. J. et al. 2006. Multivariate dispersion as a measure. of beta diversity. - Ecol. Lett. 9: 683-693.

Bernard, G. et al. 2007. Long term changes in Zostera meadows in the Berre lagoon (Provence, Mediterranean Sea).- Estuar. Coast. Shelf. Sci. 73: 617-629.

Bell, S.S. et al. 1999. Gap dynamics in a seagrass landscape. Ecosystems 2: 493-504

Bell, S.S. et al. 2006. Seagrass ecology: new contributions from a landscape perspective. - In: Larkum, A. W. D. et al. (eds), Seagrasses: biology, ecology, and conservation. Springer, pp. 625-645.

Bradley, M. P. and Stolt, M. H. 2006. Landscape-level seagrass-sediment relations in a coastal lagoon. - Aquat. Bot. 84: 121-128.

Cabaç, S. and Santos, R. 2007. Effects of burial and erosion on the seagrass Zostera noltii. - J. Exp. Mar. Biol. Ecol. 340: 204-212.

Cabaço, S. and Santos, R. 2008. The impact of sediment burial and erosion on seagrasses: A review.- Estuar. Coast. Shelf. Sci. 79: 354-366.

Dale, M. R. T. et al. 2002. Conceptual and mathematical relationships among methods for spatial analysis. Ecography 25: 558-577.

Dey, S. and Joshi, A. 2006. Stability via asynchrony in Drosophila metapopulations with low migration rates. Science 312: 434-436.

Den Boer, P.J. 1981. On the survival of populations in a. heterogeneous and variable environment. - Oecologia 50: 39-53.

de Boer, W.F. 2007. Seagrass--sediment interactions, positive feedbacks and critical thresholds for occurrence: a review. - Hydrobiologia 591: 5-24.

Duarte, C.M. 2002. The future of seagrass meadows. Environmental Conservation 29: 192-206.

Duarte, C.M.et al. 2006.Dynamics of seagrass stability and change. - In: Larkum A. W. D. et al. (eds) Seagrasses: biology, ecology and conservation. Springer, pp. 
271-294.

Frederiksen, M.et al. 2004a.Spatial and temporal variation in eelgrass (Zostera marina) landscapes: influence of physical setting. - Aquat. Bot. 78: 147-165.

Frederiksen, M.et al. 2004b.Long-term changes in area distribution of eelgrass (Zostera marina) in Danish coastal waters. - Aquat. Bot. 78: 167-181.

Furukawa, K. and Okada, T. 2006.Tokyo Bay: Its environmental status -past, present, and future - In: Wolanski, E. (eds) The Environment in Asia Pacific Harbors Springer pp. 15-34.

Glemarec, M.et al. 1997. Long-term changes of seagrass beds in the Glenan Archipelago(South Brittany). Oceanologica acta 20: 217-227.

Grimm, V.and Wissel, C. 1997. Babel, or the ecological stability discussions: an inventory and analysis of terminology and a guide for avoiding confusion. Oecologia 109: 323-334.

Guichard, F.et al. 2000. High-resolution remote sensing of intertidal. Ecosystems: A low-cost technique to link scale-dependent patterns and processes. - Limnol. Oceanogr. 45: 328-338.

Hanski, I.1994, A practical model of metapopulation dynamics. - J. Anim. Ecol. 63: 151-162.

Hanski, I. 1999. Metapopulation ecology - Oxford Univ. Press.

Hemminga, M.A. and Duarte, C.M. 2000. Seagrass ecology Cambridge Univ. Press.

Hinata, H. 2006. Effects of oceanic water intrusion on the Tokyo Bay environment. - In: Wolanski, E. (eds) The Environment in Asia Pacific Harbors. Springer pp. 67-78.

Ishii, M. et al. 2008 Long-term fluctuations of the water quality in Tokyo Bay judged from a data set of Chiba Prefecture - Bulletin of the Japanese Society of Fisheries Oceanography 79: 189-199.(in Japanese with English abstract and figures)

Jensen, J.R. 1996. Introductory digital image processing: A remote sensing perspective, 2nd ed - Prentice Hall College Div.

Kawabe, M. 1989. Sea level changes south of Japan associated with the non-large-meander path of the Kuroshio.Journal of Oceanography 45: 181-189.

Kendrick, G.A. et al.2002. Changes in seagrass coverage in Cockburn Sound, Western Australia between 1967 and 1999. - Aquat. Bot. 73: 75-87.

Kendrick, G.A.et al. 2005. Clonality in seagrasses, emergent properties and seagrass landscape - Mar. Ecol. Prog. Ser. 290: 291-296. seagrass species with different growth dynamics Ecography31: 191-200.

Ecotsu, T 1997. Long-ter in the Seto Inland Sea (Japan), especially along the coast of the Okayama Prefecture. - Oceanol. Acta. 20: 209-216

Larkum, A.W.D. and West, R.J. 1990. Long-term changes of seagrass meadows in Botany Bay, Australia. - Aquat. Bot. 37: 55-70. intertidal Zostera japonica on the western coast of Korea. - Aquat. Bot. 83: 263-280

Legendre, P. and Legendre, L. 1998. Numerical ecology 2ndEnglish ed. - Elsevier.

Levin, S.A. 1992. The problem of pattern and scale in ecology - Ecology 73: 1943-1967.
Marbá, N. and Duarte, C. M. 1995. Coupling of Seagrass (Cymodocea Nodosa) Patch Dynamics to Subaqueous dune Migration. - The Journal of Ecology 83: 381-389.

Marbá, N. and Duarte, C. M. 1999. Rhizome elongation and seagrass clonal growth. - Mar. Ecol. Prog. Ser. 174: 269-280.

Marsh Jr., J. A. .et al. 1986. Effects of temperature on photosynthesis and respiration in eelgrass (Zostera marina L.). - J. Exp. Mar. Biol. Ecol. 101: 257-267.

McRoy, C.P. 1996. The global seagrass initiative continues In: Kuo, J. et al. (eds) Seagrass biology: Proceedings of an international workshop. University of Western Australia, Nedlands, pp. 3-6.

Mills K.E. and Fonseca M.S. 2003. Mortality and productivity of eelgrass Zostera marina under conditions of experimental burial with two sediment types. - Mar. Ecol. Prog. Ser. 255: 127-134.

Nakaoka, M. and Aioi, K. 2001. Ecology of seagrasses Zostera spp. (Zosteraceae) in Japanese waters: A review. Otsuchi Marine Science 26: 7-22.

Nakaoka, M.et al. 2003 Seasonal dynamics of Zostera caulescens: relative importance of flowering shoots to net production. - Aquat. Bot. 77: 277-293.

Nakaoka, M. and Noda, T. 2004. Special feature: multiple spatial scale approaches in population and community ecology - Popul. Ecol. 46: 103-104.

Nakayama, K. 2006 Circulation processes in Tokyo Bay. - In: Wolanski, E. (eds) The Environment in Asia Pacific Harbours. Springer, Netherlands pp. 47-67.

O’Neil, R.V. and King, A.W. 1998. Homage to St. Michael: or, why are there so many books on scale?. - In: Peterson DL, Parker VT (eds) Ecological scale. ColumbiaUniv. Press, pp. 3-15.

Orth, R. J. et al. 2006. A global crisis for seagrass ecosystems. Bioscience 56: 987-996.

Pech, D. et al. 2007. Abundance variability of benthic intertidal species: effects of changing scale on patterns perception. - Ecography 30: 637-648.

Ranius, T. 2001. Constancy and asynchrony of populations of a beetle, Osmoderma eremitaliving in tree hollows. Oecologia 126: 208-215.

Robbins, B.D. and Bell S.S. 1994. Seagrass landscapes: a terrestrial approach to the marine subtidal environment Trends. Ecol. Evol. 9: 301-304.

Robbins, B.D. and Bell S.S. 2000. Dynamics of a subtida seagrass landscape: seasonal and annual change in relation to water depth. - Ecology 81: 1193-1205.

Schneider, D.C. 2001. The rise of the concept of scale in ecology. - Bioscience 51: 545-553 human-induced disturbance of seagrasses world wide. Environmental Conservation 23: 17-27.

Turner, M.G. et al. 2002. Landscape disturbance: location, pattern and dynamics - In: Gergel, S. E. and Turner, M. G. (eds) Learning landscape ecology, a practical guide to concepts and techniques. Springer.

Waycott, M. et al. 2009. Accelerating loss of seagrasses across the globe threatens coastal ecosystems. -Proc. Natl. Acad. Sci. 106: 12377

makita, T. et al. 2005. Long-term spatial dynamics of a seagrass bed on Futtsu tidal flat in TokyoBay.- Japanese Journal of Conservation Ecology 10: 129-138.(in Japanese with English summary)

Yamakita, T. and Nakaoka, M. 2009 Scale dependency in seagrass dynamics: how does the neighboring effect vary with grain of observation?. - Popul. Ecol. 51 : 33-40. 